\title{
Designing water abstraction regimes for an ever- changing and ever-varying future
}

\section{Citation}

Young, Michael D. 2014. “Designing Water Abstraction Regimes for an Ever-Changing and Ever-Varying Future." Agricultural Water Management 145 (November): 32-38. doi:10.1016/ j.agwat.2013.12.002.

\section{Published Version}

doi:10.1016/j.agwat.2013.12.002

\section{Permanent link}

http://nrs.harvard.edu/urn-3:HUL.InstRepos:13460253

\section{Terms of Use}

This article was downloaded from Harvard University's DASH repository, and is made available under the terms and conditions applicable to Other Posted Material, as set forth at http:// nrs.harvard.edu/urn-3:HUL.InstRepos:dash.current.terms-of-use\#LAA

\section{Share Your Story}

The Harvard community has made this article openly available.

Please share how this access benefits you. Submit a story.

\section{Accessibility}




\title{
Designing water abstraction regimes for an ever- changing and ever-varying future
}

\author{
Michael D. Young. Tel: +61408488538 Email: Mike.Young@adelaide.edu.au \\ Address: Faculty of Professions, The University of Adelaide, Adelaide 5005, Australia \\ Submitted for publication in Agricultural Water Management.
}

\section{Abstract}

Most of the world's water entitlement and allocation regimes evolved during periods of abundance and, hence, are not well suited to the management of water scarcity. Development of the institutional arrangements necessary to manage changing demands and supplies is in its infancy.

Design criteria for the development of a set of institutional arrangements for the robust management of scarce water resources is offered and then used to develop a generic framework for the allocation and use of water. Variations to account for differences in ground, regulated and unregulated water resources are offered. The question of how best to sequence reform of existing water entitlement and allocation regimes is also addressed.

The result is a recommendation for the use of water sharing plans to determine how much water may be used at any point in time and an unbundled suite of arrangements that enable efficient but separated management of long term and short term considerations and, also, the control of externalities.

System-wide adjustment is facilitated through the periodic revision of water sharing plans. Individual adjustment to changing circumstances is facilitated through trade in entitlements and allocations.

Before the introduction of institutional arrangements that encourage adjustment through trade it is recommended that the abstraction regime used be converted into one that accounts for return flows and allocates water according to shareholder entitlement. Seniority, beneficial-use criteria and opportunities to third parties to prevent adjustment according to pre-specified rules should be repealed. Well-designed regimes can be extended to include dam-capacity shares and allow the use of market-based instruments in delivery of water-quality objectives. Pooling can be used to lower the costs of risk management.

\section{Introduction}

If there is anything that is certain about water, it is that demand for access to it and the maximum amount that can be taken sustain-ably at any point in time must be expected to change. The search for the most appropriate way to supply access to scarce water is now part of the global water agenda.

As the clock ticks on, an increasing number of nations are becoming aware of the pressures that ever-changing economic conditions, ever-changing technologies, population growth and ongoing climatic change are placing on their water management regimes. In many countries, social preferences for arrangements that return health to degraded wetlands, rivers and aquifers are on the increase (Young, 2013). 
With a James Bond like wit, Catley-Carlson (2009) describes this suite of pressures and challenges as a cocktail to be stirred carefully.

"Take one world already being exhausted by 6 billion people. Find the ingredients to feed another 2 billion people. Add demand for more food, more animal feed and more fuel. Use only the same amount of water the planet has had since creation. And don't forget to restore the environment that sustains us. Stir very carefully." (Catley-Carlson, 2009, p.2)

Drawing attention to the global importance of preparing to deal with these challenges, the OECD (2009) warns that, by 2030, over half the people living in the world will be reliant upon access to stressed water resources.

At any point in time and place, the bottom line is that administrators should expect that, even if the water use they are responsible for looks "very right" today, in a few decades' time the way this water is used will be very different.

Given the reality of changing supply and demand conditions, how should one think about the design of a regime that determines who is entitled to access water and, in times of scarcity, how access is to be rationed?

\section{Box 1: Definitions}

System: A connected set of water bodies which may include streams, lakes, rivers and aquifers.

Regulated water system: A system where the flow of water can be controlled by determining when and how much water is released from dams and/or allowed to flow over control weirs and other similar structures.

Unregulated water system: A stream or river where there is little or no opportunity to control the rate of flow. Unregulated streams and rivers typically have no dams, weirs or locks that enable the rate of flow from one reach to another to be manipulated.

Abstraction regime: The constellation of mechanisms (entitlements, allocations licenses, permits, etc.) used to determine who, when, how and how much water may be abstracted from a water resource pool.

Entitlement: A long-term interest in or entitlement to receive allocations or be allowed to abstract water from a water body.

Allocation: A defined once-off opportunity to take water from a water body. Usually defined as a volume. Sometimes defined as a maximum rate per hour when flow conditions allow abstraction.

Return flow: The water physically withdrawn from a system and returned back to the same or a different water body following use. Many towns abstract water for drinking, washing and flushing purposes and return the majority of this water to a water body following use. Similarly, many industries abstract water for cooling purposes and then return it back to a river after use. Irrigation is often associated with the return of a significant proportion of abstracted water back to a river or aquifer.

Over-allocated: A water body with entitlements which if fully exercised would result in a rate of abstraction that is greater than that which can be sustained. 
Over-used: A water body where the quantity being abstracted is greater than that which can be sustained.

\section{Proposition}

The main proposition put forward in this paper is the observation that in order to manage this forthcoming cocktail of challenges, most countries will need to revise the ways that water entitlements, water allocations, use permits, etc. are defined. Almost all abstraction regimes that one can find around the world evolved during periods of relative water abundance and where rapid changes in technology were not common.

When viewed from this perspective, in many cases, it will be more efficient to replace the existing abstraction management regime with one that is designed specifically to enable the cost effective management of the many challenges that increasing water scarcity brings to a region. Meinzen-Dick (2013) reviews abstraction reform challenges for developing countries.

\section{Water entitlement regimes}

In this paper, the term "abstraction management regime" is used in preference to the more common "water-right" terminology (see Box 1). See Grafton and Horne (2014) for more detail on water rights terminology, especially for Australia. The water-right literature is complex and built on legal traditions that discourage the development of new precedents. When one uses baggage free language, discussion focuses on the concept and tends to leave preconceived notions behind.

In most countries, abstraction management regimes used have their roots in century old traditions and in laws that are regarded as sacrosanct (MeinzenDick, 2013). In recent years, however, a few countries have chosen to totally re-specify the way entitlements to access water are specified. Examples include Australia (Young, 2010), Chile (Bauer, 1998) and South Africa (Nieuwoudt and Backeberger, 2010).

From 1994 onwards, Australia has been replacing its traditional water licensing regimes with a new suite of water sharing regime (COAG, 2004) that have enabled entitlement and allocation markets to emerge (NWC, 2011).

In 1981, Chile introduced a new market-based framework for the allocation and management of water (Bauer, 2012).

Other countries, like China and the UK, are contemplating changing their entitlement regimes and, in particular, making them more conducive to the emergence of markets that enable people to take advantage of the opportunities that change create (DEFRA, 2011; Young, 2012a). Wu et al. (2014) describe a new approach to basin-scale water resources management based on an evapotranspiration management approach.

The reasons for pursuing each of these reforms involve a mix of economic, environmental and social considerations. Australia began with an economic reform agenda that was quickly coupled with recognition of the need to resolve a suite of environmental problems. Chile, too, began with a focus on the role of 
water in economic development. South Africa recognized the need to include water entitlement reform in the arrangements needed to escape from a socially repressive apartheid regime. When one reviews the experience of these countries, it quickly becomes clear that no country got the sequence of reforms right. In each of the cases outlined above, countries have made serious mistakes from which other countries can learn (see, for example, Bauer, 2004, 2012; Young, 2010, 2012b; Bjornlund et al., 2012; Grafton et al., 2011).

The United Kingdom has recognized that it needs to include entitlement reform in the suite of arrangements needed for it to comply with the European Community water framework directives for it to improve the health of many of its water systems with-out adverse economic impacts (DEFRA, 2011). China has recognized that water markets and very different management arrangements will be needed if it is to avoid massive water scarcity problems that would be politically unacceptable and has introduced legislation that will enable trading to emerge as a means to manage water scarcity (Liu and Bin, 2003; Huaixi and Luo, 2009).

\section{Concepts}

From first principles, how should one think about designing an administrative regime that specifies entitlements, makes allocations and controls water use?

The first design clue comes from the Tinbergen Principle. Tinbergen (1952), who among other things was awarded the first Nobel Prize in Economics, was interested in policy arrangements that would produce outcomes that are dynamically efficient. That is, the constellation of instruments used would produce efficient and equitable outcomes through time and across space AND do this continuously without a need to revise them. Focusing on this idealized state, he observed that the number of instruments used to pursue policy targets matters.

If one wishes to use a market to deliver efficient outcomes through time, there should be as many instruments as there are targets (objectives).

Applied to water, this means that water access arrangements need to be separated into their component parts. Rather than a single abstraction licence, a bundle of licence, permitting and planning arrangements are needed. Each of these instruments can then be used to pursue different objectives and, where appropriate, operate at different scales. Drawing from the notion that a property right is usually best described as a bundle of opportunities and obligations, the process of separating an authorization to abstract water at a specific location, for a specific use and in a specified manner is often called "unbundling".

In unbundled regimes, as are now used widely in Australia, separate instruments and separate institutional arrangements are used to pursue separate targets (NWC, 2011). In the best of these unbundled regimes, water licences have been replaced with shares that entitle their holder to a proportion of any allocations made to a defined pool of water (Young and McColl, 2003a). Allocations are made to this pool and distributed to shareholders if and only when water is available for allocation. The result is an arrangement that provides security by assigning $100 \%$ of the investment risk to share-holders and thereby encourages them to make efficient investment decisions. In order to ensure efficient use on a day to day basis, volumetric allocations made to shareholders are tradeable. There is no obligation to use an allocation. 
In such a regime, the opportunity to trade allocations encourages users to make efficient short-term water use decisions and the opportunity to trade shares (entitlements) encourages users to make efficient long-term investment decisions. In Australia, shares are issued in perpetuity and defined so that all water users, including aspiring ones, can increase their entitlement to a share of a water resource pool only by acquiring shares from an existing shareholder.

In parallel with these arrangements and in order to enable efficient management of local externalities, a "water-use" approval must be held and, in some supply systems, a delivery entitlement held. Whilst the resultant constellation of arrangements may seem much more complicated than the issuance of a single licence, unbundled regimes have induced considerable innovation. In Australia, the economic efficiency of water use has increased dramatically.

The second design clue comes from one of the Tinbergen's students Robert Mundell - who was awarded a Nobel Prize in Economics for the development of what has become known as the Assignment Principle.

In essence, the Assignment Principle states that in order to maximize their capacity to deliver on an objective, policy makers should assign an instrument exclusively to the pursuit of a policy target to which it is best suited ${ }^{11}$ and then never use that instrument to pursue another target. In a well-designed administrative regime, there is no instrument switching. Instead, each instrument has a specific purpose and is used only to pursue that purpose. Each instrument plays its role in assisting all in the search for the optimal tradeoff to be made between competing objectives or targets to be pursued. Instruments that operate at different scales are administered at different scales. On a daily basis, the right hand does not have to know what the left hand is doing. Each can be trusted to get on with the job (Mundell, 1960, 1962).

By way of example, in Australia's southern connected River Murray System, entitlement trading is used to encourage efficient investment and to maintain equity. Similarly, allocation trading is used to ensure that water use is efficient at any point in time. Allocations are defined by volume and readily tradeable at low cost. An allocation trade (temporary trade) from the state of Victoria to the state of South Australia can usually be completed within two days ${ }^{2}$ (NWC, 2013) and, as a result, prices now respond to climatic conditions on a daily basis. This degree of temporal and spatial efficiency in the use of resources is possible, if and only if administrators can be trusted not to interfere with allocation trading rules, for example, to pursue an environmental or regional development objective.

Derived from attempts to reduce the number of mistakes made in the pursuit of optimal monetary policy, Mundell's insight focuses on the importance of deciding which instrument should be used for which purpose and then neither changing one's mind nor being tempted to use it for two simultaneous objectives. In particular, these principles challenge the call for the

Mundell (1962) recommended computing the ratio of the effect of each instrumentt on its objective and reasoned that instruments should always be assigned to the objective with the highest ratio.

2 More than $90 \%$ of allocation trades into and out of South Australia are completed within ten days. Trades between other states in the Murray Darling Basin are faster as these regimes have been unbundled (NWC, 2013). 
development of so-called "integrated water resource management." Integration is done in the market place by individual water users operating in an environment designed to influence the decisions they make. ${ }^{3}$

The use of market mechanisms, however, is possible if and only if this does not produce perverse outcomes - especially perverse hydrological outcomes. In the world of water, failures to adequately account for return flows, connectivity between ground and surface water systems and the capture of overland flows are classic perverse outcomes.

The third design clue comes from the notion that in an ever-changing world, abstraction arrangements must be defined with hydrological integrity. That is, the arrangements must be defined in a manner that is consistent with the way water is stored, and how it flows across and flows through landscapes. In particular, it is critical that the regime take full account of return flows, connectivity between water resource pools and unregulated uses.

Unbundled abstraction regimes, if specified in a manner that have hydrological integrity, incentivise innovation. If specified without hydrological integrity, however, administrators need to intervene continuously to prevent entitlement holders from investing in ways that seek to increase their share of the system by accessing water that was previously taken by others.

Australia, for example, has found to its immense cost, that if reductions in return flows and increases in the interception of over-land flows are not included fully in the entitlement regime, a raft of social, economic and environmental problems can be expected to emerge as people take advantage of opportunities to reduce return flows and increase interception (Young and McColl, 2003b, 2008, 2009a). The solution is simple either

- entitlements need to be specified as a net entitlement - an entitlement to take a specified amount on the condition that a nominated proportion is returned back to the system; or

- the administrative regime used must require a periodic across the board reduction in allocations per share as return flows are reduced and/or interception increases.

In the western United States of America, where prior appropriation abstraction regimes are used, return flows are specified and transfer of an abstraction entitlement to another entity allowed only in ways that have no adverse return flow and other implications (Lane-Miller et al., 2013). ${ }^{4}$

Australia, however, failed to learn from US attempts to manage return flows and has found to its immense cost that reductions in return flows and increases in the interception of overland flows have to be fixed. Failure to do this is one of the reasons that so much money has had to be spent fixing up the abstraction regime used in the Murray Darling Basin. The cost of fixing these and a number of

A classic example of an assignment mistake is to discourage the efficient use of water by "taxing" entitlement and/or allocation trades in an effort to solve environmental problems in an over-allocated system. In all cases, it is more efficient to use a separate process that exposes all water users to the opportunity costs associated with water use. Examples of a separate process include the purchase of entitlements for the environment and/or the reduction of allocations made to all entitlement holders.

$4 \quad$ Because return flow obligations are specified on a case by case basis and typically wrapped up in beneficial use doctrine the result is an arrangement that has prevented allocation markets from emerging. 
other regime design mistakes has exceeded $\$ 750,000$ per irrigation business (Young, 2014).

The fourth design clue comes from another winner of a Nobel Prize in Economics-Ronald Coase. Coase, like Tinbergen and Mundell, was interested in dynamically efficient outcomes. Applied to water, the guidance that emerges from consideration of the Coase Theorem is that transaction costs need to be as low as possible (Coase, 1960).

When transaction costs are high, equity and economic efficiency issues become tangled with one another. The Coase theorem makes the observation that when property rights are fully specified and the transaction costs associated with their redistribution are zero then markets can be relied upon to produce efficiently without impinging on the equity considerations. ${ }^{5}$

Applied to water resources, the resultant design guideline is that administrators should do everything possible to get the costs of changing the way water is used as close to zero as possible.

In practice, get your transaction costs down. Audit them, bench-mark them and assign decision making responsibility so that "recommendations" can be replaced with "binding" decisions. In particular, find a way to prevent third parties from interfering with decisions made by individuals. In a democracy, this is possible if, and only if, the processes involved in determining the quantity of water that may be taken from a system and where this water may be taken are specified using arrangements that are separated (unbundled) from the instruments used to specify entitlements and allocations.

The fifth design clue comes from the observation that it is more efficient to specify entitlements so that $100 \%$ of each element of risk is assigned to one interest group. Risk assignment may vary from element to element but for dynamically efficient outcomes it is necessary always to assign $100 \%$ of that risk to one interest group. That interest group can then be made totally and completely responsible and accountable for management of that risk. If, for example, a water user is responsible totally for managing supply risk then their success will be dependent upon how well they manage that risk. Risk can also arise simply because it can be administratively expensive to design an allocation system that is perfect in every dimension. To this end, the so-called $80 / 20$ principle (Koch, 1998) can be useful. ${ }^{6}$ When it comes, for example, to the specification of exchange rates as allocations are traded from one location to another some approximation is needed in order to keep transaction costs low.

5

In his famous paper "On the problem of social cost", Coase argued the reverse of what is now described as the Coase Theorem. In his paper, Coase (1960) argued that the costs of negotiating are "sufficiently costly ... to prevent many transactions that would be carried out in a world in which the pricing system worked without cost" (p.11). "In these conditions, the initial delimitation of legal rights does have an effect on the efficiency with which the economic system operates" (p.16).

\footnotetext{
$6 \quad$ There are, however, strong parallels between this concept and the so-called Pareto Principle. Wikipedia, for example, states that "The Pareto principle (also known as the 80-20 rule, the law of the vital few, and the principle of factor sparsity) states that, for many events, roughly $80 \%$ of the effects come from $20 \%$ of the causes. Business-management consultant Joseph M. Juran suggested the principle and named it after Italian economist Vilfredo Pareto, who observed in 1906 that $80 \%$ of the land in Italy was owned by $20 \%$ of the population; he developed the principle by observing that $20 \%$ of the pea pods in his garden contained $80 \%$ of the peas" (Wikipedia, 2013).
} 
When risk assignment is vague then inefficient resource use results. If, for example, a government has a policy of providing payments to those people who do not plan adequately for a drought, then that government must expect these people not to plan for a drought and, as a result, the adverse impacts of the drought on the landscape will be worse than otherwise would have been the case (McColl and Young, 2006, 2007).

The sixth and last design clue comes from theories about robustness. Robust regimes tend to be elegant in their design and can be expected to withstand the test of time because, under duress, they work elegantly and can be expected autonomously to produce efficient, socially-acceptable outcomes (Young and McColl, 2003a, 2003b, 2005). Examples of robust arrangements include the definition of entitlements as shares that ensure that the only way one person's entitlement share can be increased is either to convince someone else to reduce their shareholding or introduce a new resource into the system so that no-one is worse off as a result of a change in the number of shares held.

Another example of a robust allocation regime is the use of double entry accounting arrangements so that allocations are first credited to an account and then debited from the account as they are either used or transferred to someone else.

\section{An emerging framework}

When viewed collectively and as summarized in Box 2 , the above design clues can be drawn together into the elements of a guiding framework for the design of any abstraction regime.

If these design clues are accepted then the first challenge is to separate systemwide instruments from those used to man-age individual decisions. At least, three groups of instruments are needed, namely:

1. Instruments for managing system-wide issues: like specifying the total amount of water that may be taken from a water body at any point in time;

2. Instruments for defining each user's interest: including the nature of each entitlement and allocations made; and

3. Instruments for managing the impacts and consequences of use: such as, for example, a requirement to meter abstractions, not to pollute, etc. 
Box 2: Principles for the design of an abstraction regime

1. Unbundle - Have at least as many instruments as there are objectives and use a separate instrument for the pursuit of each objective.

2. Certainty - Once an instrument has been assigned for pursuit of one objective, never allow it to be used to pursue another objective.

3. Hydrological integrity - Define all entitlements and allocations in a manner that is consistent with the way that water is stored, flows across and through land.

4. Facilitate trading - Keep the transaction costs associated with the transfer of entitlements, allocations, etc. as low as possible.

5. Efficient investment - Fully assign all the risks associated with an entitlement, allocation, etc. to one entity.

6. Robustness - Ensure that the constellation of interacting instruments and administrative arrangements is robust enough to withstand the test of time.

At the system scale, catchment plans can be used to define the nature of each water resource pool and the abstraction regime used to determine how water will be distributed amongst shareholders in that pool. This same plan, or for large systems, a basin plan can be used to determine how connections among water resource pools will be managed.

In practice, planning documents are used to determine the nature of systemwide opportunities and, once these have been prepared the abstraction regime is then used to share these opportunities among entitlement holders and other users. For this approach to work, it is critical that the wording used is consistent with and is nested under the planning document.

This means that entitlements should be specified in a manner that, in effect, is used to partition or share opportunities to access water in a river or an aquifer. No entitlement should ever guarantee that a volume of water will always be available. Instead, the water sharing plan should be used to define how much water is to be allocated to entitlement holders and when these allocations will be made.

Pulling all these concepts together and drawing on experience in Australia and in the success of the Falaj irrigation regimes developed many centuries ago, the state of the art in the robust design of abstraction regimes appears to involve the definition of entitlements as shares (Young, 2012a; al-Ghafri et al., 2013). Allocations in terms of volume or access time can then be made in proportion number of shares held by each entitlement holder. Building upon corporate experience, shares should be defined as unit shares so that it is possible to split and amalgamate a defined water resource. In practice, the resulting arrangements should be made as fungible as possible. That is, each sharing pool and all allocation pools should be made as large as possible so that costs associated with administering the regime can be kept as low as possible.

Shares can be defined in one of two ways. As already mentioned, the first option is to define them as a "net" entitlement to the amount of water that can be used. In "net" entitlement regimes, account is taken of return flows and, using estimates contained in water sharing plans, assumptions are made about the proportion of water that is returned following use. Flood irrigation over a light soil, 
for example, can result in as much as $50 \%$ of the water taken draining back to an unconfined aquifer. In contrast, almost all drip irrigation tends to be lost in evapotranspiration with less than $10 \%$ return-flow. The main disadvantage of this user-by-user approach is that the cost of monitoring irrigation practice and adjusting each water account for return flow is expensive.

The alternative approach, which is administratively cheaper, is to define the entitlements as a "gross" entitlement. Under robust "gross" entitlement regimes, the size of the consumptive pool is reduced as the technical efficiency of water use increases. This approach is much simpler and gives a first-mover advantage to those who are among the first to improve the technical efficiency of water use.

Both approaches have hydrological integrity. Which of the two approaches - a gross or net entitlement regime - is more appropriate depends upon the merits of encouraging the rapid adoption of technically efficient technology and the costs of monitoring use. Under a net-entitlement regime, the individual incentive to become more efficient is less than is the case when the gross-entitlement regime is used and allocations per share decreased as the mean technical efficiency of water use increases. ${ }^{7}$

A second question - which also lacks adequate theory - is the question of how best to sequence water reforms. Transitional arrangements are important. If, for example, a volumetric allocation regime is to be used to manage scarcity then there is a need first to introduce meters and establish, an administrative regime that ensures that meters are rarely tampered with and that over-use is so-heavily penalized that meter tampering is a rare event (Young,2010). Careful consideration of governance arrangements can be critical in ensuring compliance. Enforcement, for example, is much easier if those attempting to steal water are seen to be stealing it from their fellow shareholders rather than from the government.

As a regime consistent with the above framework is developed, it soon becomes clear that the role of a catchment or basin plan is to establish the rules by which water use decisions and investment decisions associated with water are made but NOT define how and where water is used. Amongst other things this means that there should be no restriction the way water is used. Water entitlements (shares) can then be made freely transferable and as a result those who find more efficient ways to manage water use can be rewarded through the market place.

One of the easiest and most robust ways lock in such a suite of incentives is to issue entitlement shares in perpetuity. The result, as already explained, is an arrangement that ensures that any increase in the amount of water taken by one person is accompanied by an arrangement that decreases use by an equivalent amount else-where. Beneficial use concepts like "use it or lose it" are replaced with an arrangement that incentivises and rewards more efficient water use.

$7 \quad$ In the case of Australia's Southern Connected River Murray system, the entitlement issued to irrigators is a gross-entitlement. Rather than doing what was originally committed to and which would have encouraged efficient investment, governments have chosen to off-set the adverse impact of increased water-use efficiency on return flows by purchasing entitlements from irrigators that are willing to sell them. In practice, this approach works but, from an economic perspective, should be seen as a subsidy to irrigators that buys back the adverse consequences of inefficient investment. 


\section{System specificity}

In the real world there are many types of water supply systems. Some involve large dams others involve the capture and, possibly, local storage of water as it flows past a farm or town. Groundwater systems involve different considerations. In Australia, abstraction regimes that involve large dams and many control structures are called "regulated systems" because the rate of flow of water through these systems can be controlled (regulated). At the other end of the spectrum are systems that are, in essence, "unregulated" because the rate of flow depends upon rainfall and the degree of abstraction.

No matter what the nature of the system and in order to facilitate low-cost trading, the challenge is to find a way to make entitlements and allocations as fungible as possible. That is, the unbundling process should be used to make each element in the administrative regime similar in form and structure. That is, every effort should be made to standardize each part of the entitlement and allocation regime and thereby deepen the opportunity for low-cost trading arrangements to emerge.

In regulated systems and if the market is deepening benefits of fungibility are to be pursued, this means that all seniority allocation regimes should be converted into share regimes and each allocation pool made as large as possible. In regulated rivers, the share pool should be at least at the scale of a river reach and in many cases, is more appropriately defined by reference to a dam or collection of dams. Allocation exchange rates can be used to adjust for transmission losses, etc. In regulated systems the carry-forward of unused water from one allocation period to the next should be possible to that regime encourages optimal management of supply risk as well as scarcity. That is, with adjustment for storage losses and subject to storage capacity, it should be possible to carry forward unused water allocations from one period to the next so that water users have to think about when as well as where water should be used.

In unregulated systems entitlements can still be defined as shares of a defined resource pool. In these systems, if allocations are defined by reference to the flow at the top of a reach, then volumetric conversion tables can be used to determine how much water may be taken at any point along that reach. Low-cost within-reach trading then becomes possible (Young and McColl, 2009b).

There is also an issue related to the degree of administrative complexity that is appropriate. In systems where a very small pro-portion of water is being taken, the regime used can be simple and inexpensive to administer. As more and more water is taken, and if one does not wish to compromise environmental objectives, more complexity is needed. In addition, one must be mindful of the costs of administering any regime (Young, 2012a). In small systems, the fixed costs of running a fully unbundled share regime may not be justified.

In large systems, there can be advantage in splitting each water pool into two or more priority sub-pools. A high-security, a general security and a low security share pool can then be set up so that supply risk can be managed at less cost to the investor.

Finally and because transaction costs need to be kept low, early effort and investment in the development of centralized entitlement registers and water accounting regimes is critical. The most efficient regimes that I am aware of rely upon the creation of centralized entitlement registers that define "who" owns "what" entitlement. Under such a regime, if anyone wants to secure an 
entitlement to access water, the only way they can do this is to enter into a contract with an existing entitlement holder to change that register.

Similarly, if a person wishes to record a financial interest in that entitlement - for example, by registering a mortgage, the regime should provide that the only way to do this is to record that interest on the register. In parallel, with this arrangement, the regime should make it impossible to record a third party interest in an allocation so that allocation trades can occur instantaneously.

\section{Concluding remarks}

In the past, most water economists and others have been wary of recommending a fundamental redesign of water abstraction regimes and, instead, have opted to focus on opportunities to make marginal improvements by, for example, recommending the introduction of arrangements that allow trade in water allocations.

In this paper, it is suggested that, in most if not all instances, there is a strong case for including the re-specification of abstraction licensing arrangements in the suite of options to be considered. Implementation of transformation reforms requires careful attention to detail. Upfront investment in the development of new administrative capabilities is necessary and careful communication with stakeholders essential. When the case for change is well thought through and well communicated, however, the returns can be significant. Abstraction regime revision is not an easy process. Without great care, massive mistake can be made and those with a vested interest in the existing regime can be expected to oppose change at every step in the process. Further research on reform sequencing and implementation is needed (Young, 2014).

\section{Acknowledgements}

First and foremost this paper has benefited from the opportunity to work closely with the late Jim McColl. Jim had an outstanding mind that could cut through the detail and help find robust solutions to complex problems. His contribution to the development of more robust ways to manage natural resources in Australia will be missed. The paper has benefited also from the opportunity to prepare reports for and to work closely with those responsible for the development of options for the reform of water management in Australia, Canada, the United Kingdom, the Netherlands, New Zealand and the OECD. The contribution of these people to the framework set out in this paper is acknowledged with appreciation. As always, responsibility for the content of this paper remains with the author.

\section{References}

al-Ghafri, A., Nash, H., al-Sarmi, M., 2013. Timing water shares in Wādī Banī KharūB,Sultanate of Oman. In: Proceedings of the Seminar for Arabian Studies 2013, vol. 43, pp. 1-10.

Bauer, C.J., 1998. Against the Current: Privatization, Water Markets and the State in Chile. Kluwer, Boston.

Bauer, C.J., 2004. The Siren Song: Chilean Water Law as a Model for International Reform. Resources for the Future, Washington, DC. 
Bauer, C.J., 2012. The experience of water markets and the market model in Chile. In: Maestu, J. (Ed.), Water Trading and Global Water Scarcity. International Experiences. RFF Press/Taylor and Francis/Routledge, UK, pp. 130-143.

Bjornlund, H., Wheeler, S., Rossini, P., 2012. Water markets and their environmental, social and economic impact in Australia. In: Maestu, J. (Ed.), Water Trading and Global Water Scarcity. International Experiences. RFF Press/Taylor and Fran-cis/Routledge, UK, pp. 68-93.

Catley-Carlson, M., 2009. The bubble is close to bursting: a forecast of the main economic and geopolitical water issues likely to arise in the world during the next two decades. In: Draft for Discussion at the World Economic Forum Annual Meeting 2009, Available at: www.weforum.org/reports/bubble-close-bursting.

COAG (Council of Australian Governments), 2004. Intergovernmental Agreement on a National Water Initiative between the Commonwealth of Australia and the Governments of New South Wales, Victoria, Queensland, South Australia, the Australian Capital Territory and the Northern Territory.

Coase, R.F., 1960. The problem of social cost. Journal of Law and Economics 3, 144. DEFRA (Department for Environment, Food \& Rural Affairs), 2011. Water for Life: Market Reform Proposals. DEFRA, London.

Grafton, R.Q., Horne, J., 2014. Water Markets in the Murray-Darling Basin. Agricultural Water Management 145, 61-71.

Grafton, R., Libecap, G., Landy, C., O’Brien, B., 2011. An Integrated Assessment of Water Markets: A Cross-Country Comparison. Review of Environmental and Economic Policy 5, vol. 2., pp. 219-239.

Huaixi, Luo, 2009. Water Trading, What Can We Learn From Each Other?, Available at http://www.ilsac.gov.au/InternationalLegalCooperation/ AustraliaChinaLegalProfessionDevelopmentProgram/ACLPDProgram2009/ Documents/Water-Trading-What-Can-We-Learn-From-Each-Other-Luo-HuaixiReport.pdf

Koch, R., 1998. The 80-20 Principle: The Secret to Success by Achieving More with Less. DoubleDay, New York.

Lane-Miller, C., Wheeler, S., Bjornlund, H., Connor, J., 2013. Acquiring water for the environment: lessons from natural resources management. Journal of Environmental Policy and Planning, http://dx.doi.org/10.1080/1523908X. 2013.807210.

Liu, Bin, 2003. Water rights in China. In: International Working Conference on Water Rights: Institutional Options for Improving Water Allocation, February 12-15, 2003, Hanoi, Vietnam, Available at http://citeseerx.ist. psu.edu/viewdoc/download?doi=10.1.1.195.3157\&rep=rep1\&type $=p d f$

McColl, J., Young, M., 2006. Drought and structural adjustment. Farm Policy Journal 3 (2), 13-21.

McColl, J.C., Young, M.D., 2007. Managing Change: Australian Structural Adjustment Lessons for Water. CSIRO Land and Water Report No. 16/05.

Meinzen-Dick, R., 2013. Property Rights and Sustainable Irrigation: A Developing Country Perspective, IFPRI working paper.

Mundell, R.A., 1960. The monetary dynamics of international adjustment under fixed and flexible exchange rates. Quarterly Journal of Economics 74, 227-257. Mundell, R.A., 1962. The Appropriate Use of Monetary and Fiscal Policy for Internal 
and External Stability. Staff Papers - International Monetary Fund 9, vol. 1., pp. 70-79.

Nieuwoudt, W., Backeberger, G., 2010. Application of economic instruments, tradable licences and good governance for sustainable irrigation water conservation in South Africa. In: Bjornlund, H. (Ed.), Incentives and Instruments for Sustain-able Irrigation. WIT Press, Southampton, UK.

NWC, 2011. Water Markets in Australia: A Short History. National Water Commission, Canberra.

NWC, 2013. Australian Water Markets: Trends and Drivers 2007-08 to 2011-12. National Water Commission, Canberra.

OECD, 2009. Managing Water for All: An OECD Perspective on Pricing and Financing. OECD, Paris.

Tinbergen, J., 1952. On the Theory of Economic Policy. North-Holland Publishing Company, Amsterdam.

Wikipedia, 2013. Pareto principle, Available at: http://en.wikipedia.org/ wiki/Pareto principle.

Young, M.D., 2010. Environmental Effectiveness and Economic Efficiency of Water Use in Agriculture, The Experience of and Lessons from the Australian Water Reform Programme. Background report prepared for OECD study, 2010. Sustainable Management of Water Resources in Agriculture. Available at: www.oecd.org/water

Young, M.D., 2014. Trading into trouble. In Easter, W. and Huang, Q. (Eds) Water Markets for the $21^{\text {st }}$ Century: What we have learned? Westview Press, Boulder.

Young, M.D., 2013. Investing in Water Services, Infrastructure, Policies and Management. In Young, M. and Esau, C. (Eds) Investing in Water for a Green Economy - Services, Infrastructure, Policies and Management. Routledge, Milton Park and New York, 319 pages.

Young, M.D., 2012a. A framework for the allocation and management of water in England and Wales. UCL Environment Institute and The University of Adelaide

Young, M.D., 2012b. Trading into and out of Trouble. Australian's Water Allocation and Trading Experience, in: Maestu, J. (Ed.), Water Trading and Global Water Scarcity. International Experiences. RFF Press/Taylor and Francis/Routledge, UK, pp. 94-112.

Young, M.D., McColl, J.C., 2009a. Double Trouble: The Importance of Accounting for and Defining Water Entitlements Consistent with Hydrological Realities. Australian Journal of Agricultural and Resource Economics 53, 1, 1935.

Young, M.D. and McColl, J.C. 2009b. Shepherding water: Unregulated water allocation and management. Droplet 15. Available at www.myoung.net.au Young, M.D., McColl, J.C., 2008. Grounding Connectivity: Do Rivers have Aquifer Rights? Droplet 13. Available at: www.myoung.net.au/water. 